\title{
Annealing time effect on CIGS thin films
}

\section{Utku Canci Matur}

Assistant Professor, Istanbul Gedik University, Istanbul, Turkey (corresponding author: utkucancimatur@gmail.com)
Nilgün Baydoğan

Professor, Energy Institute, Istanbul Technical University, Istanbul, Turkey

Chalcopyrite copper indium gallium (di)selenide ( $\mathrm{Cu}(\mathrm{In}, \mathrm{Ga}) \mathrm{Se}_{2}$ (CIGS)) thin film has been examined as an absorber layer for solar cells because of its suitable absorption value, stability and economy in manufacture. CIGS thin films belong to the I-III-VI2 group of the periodic table with the appropriate direct bandgap (1.5 eV). In this study, CIGS thin films were annealed at $\sim 200^{\circ} \mathrm{C}$ for four different annealing times $(15,30,45$ and $60 \mathrm{~min})$ to investigate the effect of the annealing time on the crystalline structure and optical properties of CIGS thin films prepared by using the sol-gel dip-coating technique. CIGS thin films annealed at $-200^{\circ} \mathrm{C}$ for $60 \mathrm{~min}$ were found to have the best structural and optical properties in this study. As the crystallite size increased with the rise in the annealing time, the lattice strain decreased, indicating the elimination of crystallite defects in the CIGS thin-film structure. Hence, the structural changes affected the optical properties slightly and the rise in the optical absorbance $(A \%)$ resulted in a decrease in the optical transmittance $(T \%)$.

\author{
Notation \\ $A \%$ absorbance $(\%)$ \\ $D \quad$ average crystal size \\ $E_{\mathrm{g}} \quad$ forbidden energy bandgap \\ $h v \quad$ energy of a photon (eV) \\ $k \quad$ constant related to the crystallite shape \\ T\% transmittance (\%) \\ $\alpha \quad$ absorption coefficient \\ $\beta \quad$ full width at half maximum \\ $\varepsilon \quad$ lattice strain \\ $\theta_{\mathrm{B}} \quad$ Bragg's angle of the related peak \\ $\lambda$ wavelength of the $\mathrm{X}$-ray radiation
}

\section{Introduction}

Chalcopyrite copper indium gallium (di)selenide $\left(\mathrm{Cu}(\mathrm{In}, \mathrm{Ga}) \mathrm{Se}_{2}\right.$ (CIGS)) thin film is a well-known p-type flexible absorber layer for thin-film solar cell applications due to its high absorption coefficient $\left(>10^{5} \mathrm{~cm}^{-1}\right)$, and its optimum energy bandgap is $1.5 \mathrm{eV}^{1}$ CIGS thin films have a tunable direct energy bandgap that can be changed from $1.04 \mathrm{eV}(\mathrm{CIS})^{2}$ to $2.4 \mathrm{eV}(\mathrm{CuGaSe})^{3}$ by increasing the gallium (Ga) amount. CIGS thin-film solar cells have high conversion efficiency among all thin-film polycrystalline solar cells. An efficiency of $23.35 \%$ has been reported for $\mathrm{CIGS}^{4}$ and cadmium telluride (CdTe). ${ }^{5}$ CIGS thin films were produced by many different methods, such as high vacuum thermal evaporation, ${ }^{6}$ pulsed electron growth, ${ }^{7}$ metal-organic chemical vapor deposition, ${ }^{8}$ molecular beam epitaxy $^{9}$ and pulsed laser magnification. ${ }^{10}$ CIGS chalcopyrite is well known for being more resistant to radiation damage than other common semiconductor thin films, such as silicon ( $\mathrm{Si}$ ), gallium arsenide $(\mathrm{GaAs})$, cadmium sulfide $(\mathrm{CdS})$ and gallium nitride $(\mathrm{GaN}),{ }^{11}$ which makes CIGS thin film a good candidate for usage in satellite applications. There were some research studies about the effect of ionizing radiation ${ }^{12-16}$ and annealing. However, these are not enough yet for explaining the details of the structural and optical properties of CIGS thin films.
In this study, CIGS thin films were deposited by the sol-gel dipcoating technique using a different and unique recipe, which is economical and easily applicable. ${ }^{17-19}$ CIGS thin films were annealed at $\sim 200^{\circ} \mathrm{C}$ for four different durations $(15,30,45$ and $60 \mathrm{~min})$ to investigate the effect of the annealing time on the crystalline structure and optical properties of CIGS thin films. The thin films annealed in air atmosphere show low values of transmission and suitable absorption in the wavelength range of interest. The increase in annealing time enhanced the structural and optical properties of the CIGS thin films. The high absorption coefficient and radiation hardness make CIGS thin films good candidates for space application. ${ }^{20}$

\section{Experimental procedure}

The precursor solution for depositing CIGS films by the sol-gel dip-coating method was prepared from copper (II) nitrate trihydrate $\left(\mathrm{Cu}\left(\mathrm{NO}_{3}\right)_{2} \cdot 3 \mathrm{H}_{2} \mathrm{O} ; 99.999 \%\right)$, indium nitrate trihydrate $\left(\mathrm{In}\left(\mathrm{NO}_{3}\right)_{2} \cdot 3 \mathrm{H}_{2} \mathrm{O} ; \quad 99.999 \%\right)$ and gallium nitrate hydrate $\left(\mathrm{Ga}\left(\mathrm{NO}_{3}\right)_{3} \cdot \mathrm{H}_{2} \mathrm{O} ; \quad 99.9 \%\right)$, and ethanol, diethanolamine $\left(\mathrm{HN}\left(\mathrm{CH}_{2} \mathrm{CH}_{2} \mathrm{OH}\right)_{2}\right)$ and hydrochloric acid $(\mathrm{HCl})$ were added to the solution as a solvent and a stabilizer. ${ }^{12}$ The cleaned substrates were withdrawn in the solution by employing a computercontrolled dip coater (KSV LMX2), and in every withdrawing process, the films were preheated on a hot plate at $100^{\circ} \mathrm{C}$ in air for $10 \mathrm{~min}$; this process was repeated five times and then the films were annealed at $200^{\circ} \mathrm{C}$ for $15,30,45$ and $60 \mathrm{~min}$ in a fanassisted oven. ${ }^{21,22}$

\section{Results and discussion}

\subsection{Changes in the structural properties of CIGS thin films at different annealing times}

The CIGS thin films were grown through the sol-gel dip-coating technique. The CIGS thin films coated with five layers were withdrawn at the same speed $(60 \mathrm{~mm} / \mathrm{min})$ and then exposed to four different annealing times in under atmospheric conditions, 
$15,30,45$ and $60 \mathrm{~min}$, at $200^{\circ} \mathrm{C}$. The changes in the structural characterization of CIGS thin films annealed at different annealing times were examined by X-ray diffraction (XRD) analysis. The full width at half maximum (FWHM) $(\beta)$ values of samples were determined by using the Fityk program, ${ }^{23}$ and the average crystal size $(D)$ was calculated using the Debye-Scherrer formula (Equation). ${ }^{24}$ The lattice strain $(\varepsilon)$ was calculated by using the Williamson and Hall method (Equation 2). ${ }^{25}$

1. $D=\frac{k \lambda}{\beta \cos \theta_{\mathrm{B}}}$

2. $\beta \cos \theta=\frac{k \lambda}{D}+2 \varepsilon \sin \theta$

where $\lambda$ is the wavelength of the $\mathrm{X}$-ray radiation (1.5405 $\AA$ ); $\theta_{\mathrm{B}}$ is the Bragg's angle of the related peak; $\beta$ is the FWHM in radians; and $k$ is the constant related to the crystallite shape and is taken as 0.94. Lattice strain is a measure of the distribution of lattice constants resulting from crystal defects such as lattice displacements. The crystallite size and the lattice strain affect the Bragg peak depending on the increase in peak width and intensity, which changes the peak value of $2 \theta^{26}$

The XRD analysis indicates that the gallium selenide $\left(\mathrm{Ga}_{2} \mathrm{Se}_{3}\right)$ crystalline structure has a diffraction plane at the (004) diffraction plane and the copper gallium selenide $\left(\mathrm{CuGaSe}_{2}\right)$ crystalline structure has a diffraction plane at the (200) diffraction plane. ${ }^{27}$ Figures 1-4 show the XRD analysis results of CIGS thin films annealed at four different temperatures $(15,30,45$ and $60 \mathrm{~min})$. Moreover, all annealed samples show the diffraction peaks corresponding to the crystal structure of chalcopyrite-type CIGS. There is an increase in the crystalline size with the rise in the annealing time, and the crystalline size was determined by using the Debye-Scherrer formula. For the (004) diffraction plane, the

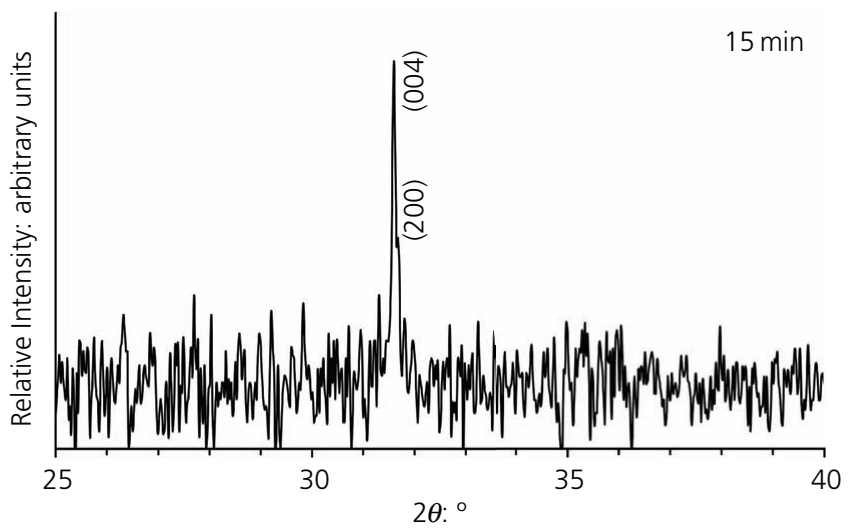

Figure 1. XRD patterns of CIGS thin films annealed for $15 \mathrm{~min}$

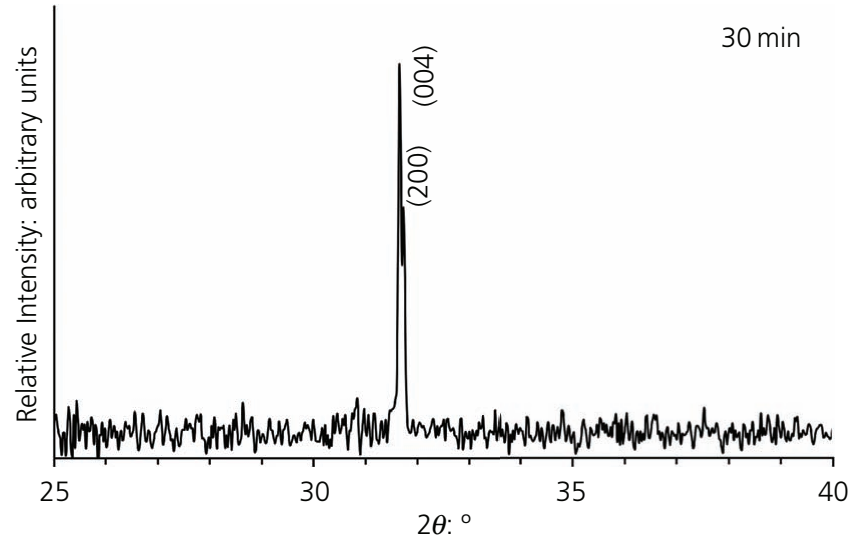

Figure 2. XRD patterns of CIGS thin films annealed for $30 \mathrm{~min}$

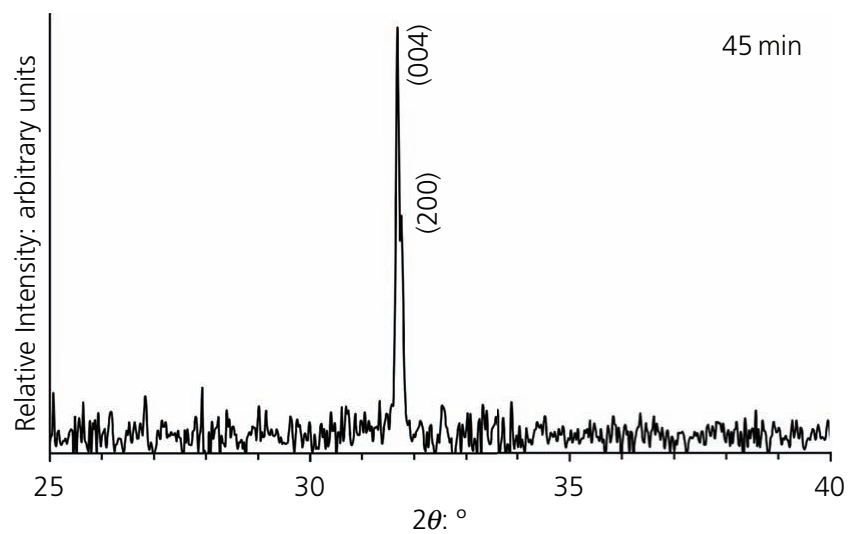

Figure 3. XRD patterns of CIGS thin films annealed for $45 \mathrm{~min}$

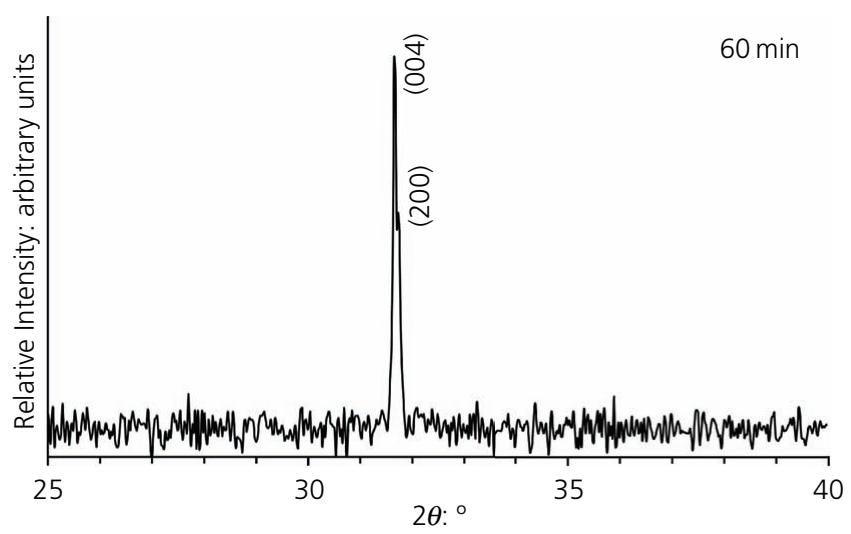

Figure 4. XRD patterns of CIGS thin films annealed for 60 min

rise in the crystalline size was determined at $D_{15 \min }=80.58 \mathrm{~nm}$ as a result of the $15 \mathrm{~min}$ annealing time. Furthermore, the annealing time at $30 \mathrm{~min}$ resulted in an increase in the crystalline size at $D_{30 \min }=107.45 \mathrm{~nm}$. When the annealing time increased to $45 \mathrm{~min}$, the crystalline size reached $D_{45 \mathrm{~min}}=108.85 \mathrm{~nm}$. The 
annealing time at 60 min led to an increase in the crystalline size at $D_{60 \mathrm{~min}}=111.75 \mathrm{~nm}$.

Analysis of the changes in strain broadening was performed by using the Williamson and Hall method. The lattice strain on the peak broadening indicated a rise with the increase in the annealing temperature. The lattice strain decreased from 0.0033 to 0.0024 when the annealing time rose from 15 to $30 \mathrm{~min}$. There was a saturation range for the lattice strain (at $\varepsilon=0.0024$ ) when the annealing time rose from 30 to $60 \mathrm{~min}$. For the different annealing times, the lattice strain was determined as $\varepsilon_{15 \mathrm{~min}}=$ $0.0033, \varepsilon_{30 \mathrm{~min}}=0.0024, \varepsilon_{45 \min }=0.0024$ and $\varepsilon_{60 \mathrm{~min}}=0.0024$ by using the Williamson and Hall method.

The intensity of the orientation in the diffraction plane $(004 ; 200)$ and the crystallite size increased with the rise in the annealing time. The XRD patterns of CIGS thin films annealed for $60 \mathrm{~min}$ reached the highest diffraction peak intensity. The XRD analysis indicated that the increase in annealing time caused the crystalline growth and improvement in the structural formation of the triplet $(\mathrm{CuGaSe})$, binary $\left(\mathrm{Ga}_{2} \mathrm{Se}_{3}\right)$ and chalcopyrite CIGS compounds.

Figure 5 presents the XRD diffraction patterns of the CIGS thin films at four different annealing times to compare the variations in FWHM and the changes in peak position.

The increase in the annealing time improved the crystalline properties of the films. ${ }^{28}$ The additional weak shoulder peak at $2 \theta=31.72^{\circ}$ was related to the presence of the $\mathrm{CuGaSe}_{2}$ (200) phase. ${ }^{29,30}$ The first and the second strongest diffraction peaks (in Figure 5) are located at $2 \theta=31.64^{\circ}$ (at the (004) diffraction plane) and $2 \theta=31.72^{\circ}$ (at the (200) diffraction plane) indicating the CIGS crystal structure (annealed for $60 \mathrm{~min}$ ). The peak position (in Figure 5) has changed slightly, and the peak intensity has increased clearly with the increase in the annealing time. When the annealing time reached $60 \mathrm{~min}$, the $\mathrm{Ga}_{2} \mathrm{Se}_{3}$ (at the 004 diffraction plane) and $\mathrm{CuGaSe}_{2}$ (at the 200 diffraction plane) peaks become more intense and the crystallinity rose from 80.58 to $111.75 \mathrm{~nm}$. The CIGS thin film annealed at $200^{\circ} \mathrm{C}$ exhibited a strong peak and an additional weak shoulder peak at $2 \theta=31.72^{\circ}$. It was assumed that this shoulder peak is related to the existence of the $\mathrm{CuGaSe}_{2}$ secondary phase, with the symmetry of lattice vibrations different from that of chalcopyrite. ${ }^{29}$ The increase in the annealing time led to an increase in peak intensity and crystallinity, which presented as the strong peak.

\subsection{Optical properties of CIGS thin films annealed at different annealing times}

The changes in the optical absorbance of CIGS thin film annealed at $\sim 200^{\circ} \mathrm{C}$ for four different annealing times were determined by using optical transmittance and reflectance in the range 190-1100 nm, shown in Figure 6. It was determined that the absorption of the CIGS thin film increased with the decrease in the transmittance, depending on the increase in the annealed time required to reach $\sim 200^{\circ} \mathrm{C}$. In the absorption process, the energy of the incoming photon excites an electron from a lower to a higher energy state. ${ }^{30}$

The forbidden energy bandgap $\left(E_{\mathrm{g}}\right)$ was calculated by taking the equation used for direct transition regarding Mott and Davis ${ }^{31}$ in Figure 7 by Equation 3 .

3. $(\alpha h v)^{2}=A\left(\alpha h v-E_{\mathrm{g}}\right)$

where $A$ is a constant and $E_{\mathrm{g}}$ is the bandgap energy. Determining $E_{\mathrm{g}}$ involves plotting a graph of $(\alpha h v)^{2}$ as a function of photon energy $h v$; the linear part of the graph is plotted with an intercept on $h v$ axis, given the energy band values of thin films, as shown in Figure 7. This change indicated the increase in the absorption coefficient as the forbidden energy bandgap $\left(E_{\mathrm{g} 30 \mathrm{~min}}=2.16 \mathrm{eV}\right.$; $\left.E_{\mathrm{g} 45 \min }=2.10 \mathrm{eV} ; E_{\mathrm{g} 60 \min }=2 \mathrm{eV}\right)$ decreased. The energy

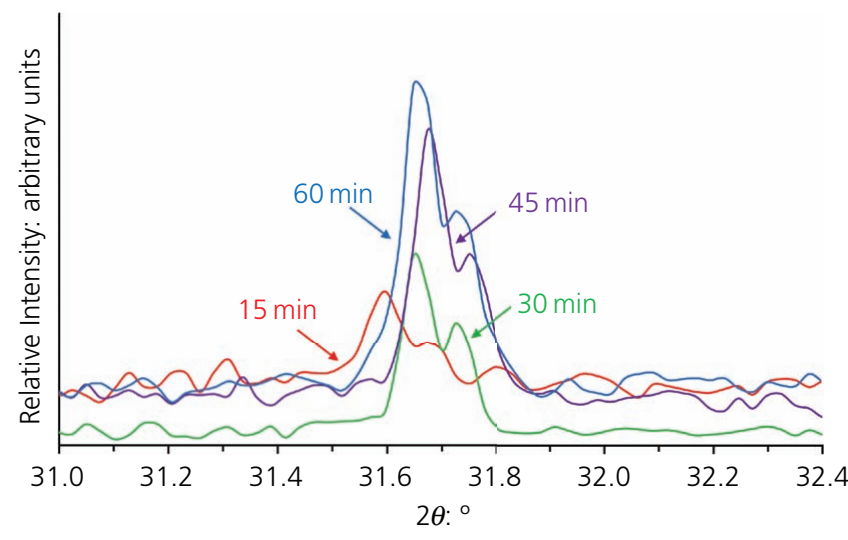

Figure 5. XRD patterns of CIGS thin films annealed at four different times

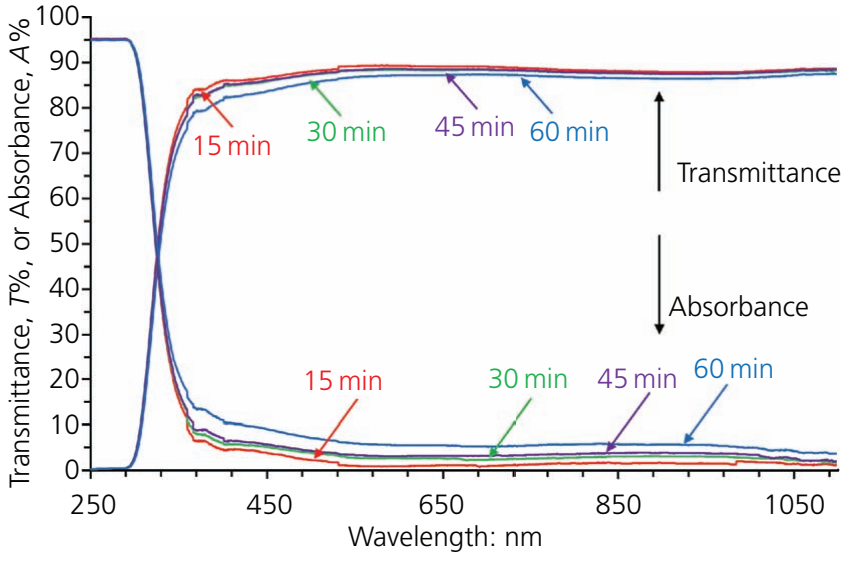

Figure 6. Optical transmittance and absorbance of CIGS thin films 


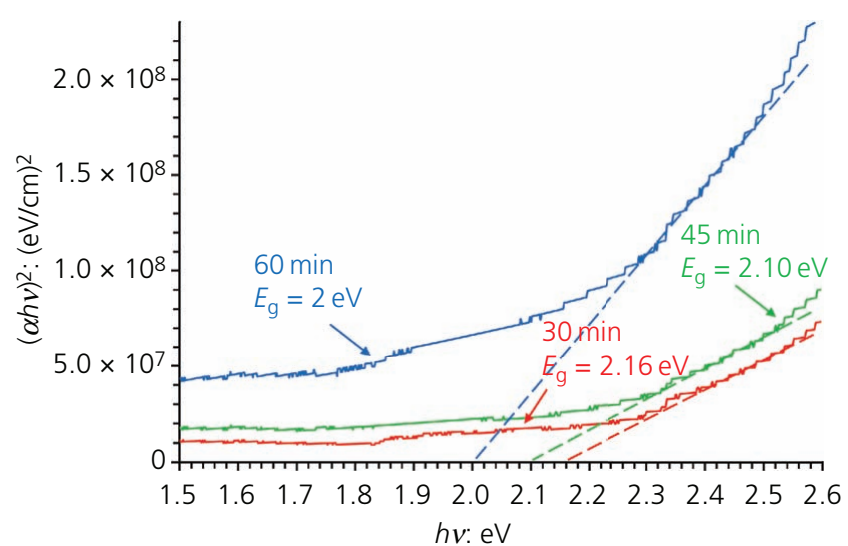

Figure 7. Energy bandgap of CIGS thin films

bandgap has decreased slightly with the increase in annealing time.

XRD analysis results clearly revealed that chalcopyrite-type CIGS crystals were grown at room temperature through the sol-gel dipcoating technique. Furthermore, the annealing of the films at a temperature of $200^{\circ} \mathrm{C}$ with various rises in annealing time (from 15 to $60 \mathrm{~min}$ ) improved the optical absorption as a result of the decrease in optical transmittance. The decrease in the energy bandgap was related to the improvement in crystallinity.

\section{Conclusion}

The rise in the annealing time supported the increase in the crystallite size. The decrease in the lattice strain is attributed to the decrease in crystallite defects in the CIGS thin-film structure. Moreover, the rise in the annealing time improved the absorption by increasing transmission along with the enhancement of structural characteristics of the CIGS thin film coated by the sol-gel dip-coating method. The optical transmittance decreased slightly with the increase in the annealing time. The increase in the annealing time from 15 to $60 \mathrm{~min}$ improved the crystallinity of the thin film with the decrease in the energy bandgap. It was determined that there was a relation between the decrease in the optical bandgap and the rise in the annealing time of the CIGS thin film.

\section{REFERENCES}

1. Kodigala SR (2011) $\mathrm{Cu}\left(\mathrm{In}_{1-x} \mathrm{Ga}_{x}\right) \mathrm{Se}_{2}$ Based Thin Film Solar Cells. Academic Press, Burlington, MA, USA, vol. 35

2. Caballero R and Guillen C (2005) $\mathrm{CuInSe}_{2}$ formation by selenization of sequentially evaporated metallic layers. Solar Energy Materials and Solar Cells 86(1): 1-10.

3. Mudryi A, Bodnar IV, Gremenok VF et al. (1998) Free and bound exciton emission in $\mathrm{CuInSe}_{2}$ and $\mathrm{CuGaSe}_{2}$ single crystals. Solar Energy Materials and Solar Cells 53(3-4): 247-253.

4. Green MA, Dunlop ED, Levi DH et al. (2019) Solar cell efficiency tables (version 54). Progress in Photovoltaics: Research and Applications 27(7): 565-575.

5. Romanyuk YE, Hagendorfer H, Stücheli P et al. (2015) All solutionprocessed chalcogenide solar cells - from single functional layers towards a $13.8 \%$ efficient CIGS device. Advanced Functional Materials 25(1): 12-27.

6. Seyrling S, Calnan S, Bücheler S et al. (2009) $\mathrm{CuIn}_{1-x} \mathrm{Ga}_{x} \mathrm{Se}_{2}$ photovoltaic devices for tandem solar cell application. Thin Solid Films 517(7): 2411-2414.

7. Rampino S, Bronzoni M, Colace L et al. (2015) Low-temperature growth of single-crystal $\mathrm{Cu}(\mathrm{In}, \mathrm{Ga}) \mathrm{Se}_{2}$ films by pulsed electron deposition technique. Solar Energy Materials and Solar Cells 133: 82-86.

8. Choi I and Lee D (2007) Preparation of $\mathrm{CuIn}_{1-x} \mathrm{Ga}_{x} \mathrm{Se}_{2}$ films by metalorganic chemical vapor deposition using three precursors. Thin Solid Films 515(11): 4778-4782.

9. Islam MM, Ishizuka S, Yamada A et al. (2009) CIGS solar cell with MBE-grown ZnS buffer layer. Solar Energy Materials and Solar Cells 93(6-7): 970-972.

10. Jo YH, Mohanty BC and Cho YS (2010) Crystallization and surface segregation in $\mathrm{CuIn}_{0.7} \mathrm{Ga}_{0.3} \mathrm{Se}_{2}$ thin films on $\mathrm{Cu}$ foils grown by pulsed laser deposition. Applied Surface Science 256(22): 6819-6823.

11. Flitsiyan E, Schwarz C, Chernyak K et al. (2011) Neutron irradiationinduced enhancement of electronic carrier transport in $\mathrm{ZnO}$. Radiation Effects and Defects in Solids 166(2): 104-108.

12. Matur UC and Baydogan N (2017) Changes in gamma attenuation behaviour of sol-gel derived CIGS thin film irradiated using Co-60 radioisotope. Journal of Alloys and Compounds 695: 1405-1413.

13. Baydogan N and Tugrul AB (2014) The effect of neutron and mixed gamma and neutron irradiation on the solar properties of borosilicate glass. Research on Chemical Intermediates 40(1): 299-306.

14. Baydogan N, Ozdemir O and Cimenoglu H (2013) The improvement in the electrical properties of nanospherical $\mathrm{ZnO}: \mathrm{Al}$ thin film exposed to irradiation using a Co-60 radioisotope. Radiation Physics and Chemistry 89: 20-27.

15. Baydogan N and Tugrul A (2013) Dose depth and penetration of light dependence in the irradiated optical glass by reactor neutrons. Optical Materials 36(2): 489-494.

16. Baydogan N and Tugrul A (2012) Borosilicate glass for gamma irradiation fields. Solid State Sciences 14(11): 1692-1697.

17. Evcin A, Arli E, Baz Z, Esen R and Sever EG (2017) Characterization of $\mathrm{Ag}-\mathrm{TiO}_{2}$ powders prepared by sol-gel process. Acta Physica Polonica A 132(3): 608-611.

18. Çiçek Bezir N, Evcin A, Kayali R, Özen M and Esen K (2017) Comparison of five-layered $\mathrm{ZrO}_{2}$ and single-layered $\mathrm{Ce}$, Eu, and Dydoped $\mathrm{ZrO}_{2}$ thin films prepared by sol-gel spin coating method. Acta Physica Polonica A 132(3): 612-616.

19. Göde F, Yavuz F and Kariper I (2015) Preparation and characterization of nanocrystalline $\mathrm{PbS}$ thin films produced by chemical bath deposition. Acta Physica Polonica A 128(2-B): B215-B218.

20. Suvanam SS, Larsen J, Ross $\mathrm{N}$ et al. (2018) Extreme radiation hard thin film CZTSSe solar cell. Solar Energy Materials and Solar Cells 185: $16-20$.

21. Matur UC, Akyol S, Baydogan N and Cimenoglu H (2015) The characteristic behaviors of solgel-derived CIGS thin films exposed to the specific environmental conditions. In Energy Systems and Management (Bilge A, Toy A and Günay M (eds)). Springer, Cham, Switzerland, pp. 179-191.

22. Matur UC and Baydogan N (2017) Sol-gel derived Cu(In,Ga)Se $\mathrm{Se}_{2}$ thin film solar cell. Journal of Nanoelectronics and Optoelectronics 12(4): 352-358.

23. Wojdyr M (2010) Fityk: a general-purpose peak fitting program. Journal of Applied Crystallography 43(5-1): 1126-1128.

24. Cullity BD (1956) Elements of X-ray Diffraction. Addison-Wesley, Reading, MA, USA.

25. Mote V, Purushotham $Y$ and Dole B (2012) Williamson-Hall analysis in estimation of lattice strain in nanometer-sized $\mathrm{ZnO}$ particles. Journal of Theoretical and Applied Physics 6(1): 1-8. 
26. Zak AK, Majid HA, Abrishami ME and Yousefi R (2011) X-ray analysis of $\mathrm{ZnO}$ nanoparticles by Williamson-Hall and size-strain plot methods. Solid State Sciences 13(1): 251-256.

27. Bi J, Ao J, Jeng MJ et al. (2017) Three-step vapor $\mathrm{Se} / \mathrm{N}_{2} /$ vapor $\mathrm{Se}$ reaction of electrodeposited $\mathrm{Cu} / \mathrm{In} / \mathrm{Ga}$ precursor for preparing $\mathrm{CuInGaSe} \mathrm{S}_{2}$ thin films. Solar Energy Materials and Solar Cells 159: 352-361.

28. Ghafouri V, Ebrahimzad A and Shariati M (2013) The effect of annealing time and temperature on morphology and optical properties of $\mathrm{ZnO}$ nanostructures grown by a self-assembly method. Scientia Iranica 20(3): 1039-1048.
29. Zaretskaya EP, Gremenok VF, Riede V et al. (2003) Raman spectroscopy of CuInSe $\mathrm{In}_{2}$ thin films prepared by selenization. Journal of Physics and Chemistry of Solids 64(9-10): 1989-1993.

30. Javed A (2007) Preparation and study of the structural, optical and electrical properties of $\mathrm{Cu}(\mathrm{In}, \mathrm{Ga}) \mathrm{Se}_{2}$ thin films. Turkish Journal of Physics 31(5): 287-294.

31. Mott NF and Davis EA (2012) Electronic Processes in Non-crystalline Materials. Oxford University Press, Oxford, UK.

\section{How can you contribute?}

To discuss this paper, please submit up to 500 words to the journal office at journals@ice.org.uk. Your contribution will be forwarded to the author(s) for a reply and, if considered appropriate by the editor-in-chief, it will be published as a discussion in a future issue of the journal.

ICE Science journals rely entirely on contributions from the field of materials science and engineering. Information about how to submit your paper online is available at www.icevirtuallibrary.com/page/authors, where you will also find detailed author guidelines. 